\title{
Políticas públicas ambientais na Amazônia: um estudo do PROAMBIENTE em Roraima
}

\section{Environmental public policies in Amazon: a field research in Proambiente in Roraima}

Luciano Monteiro do Amaral - Mestre em Economia e servidor do Instituto Federal de Educação, Ciência e Tecnologia de Roraima, Boa Vista-RR. E-mail: luciano.amaral@ifrr.edu.br

Sandra Maria Franco Buenafuente - Ph.D em Economia Internacional e Desenvolvimento e em Teoria Econômica; professora associada da Universidade Federal de Roraima/UFRR, Boa Vista-RR. E-mail: sanma239@hotmail.com

\section{Resumo}

Este artigo tem como objetivo descrever os fatores que contribuem para a falta de efetividade na aplicação das políticas públicas ambientais para a Amazônia e como estas questões influenciaram na consecução das metas da política do Proambiente, no vale do Apiaú, município de Mucajaí, estado de Roraima. O estudo de caso se deu por meio de uma pesquisa descritiva e de campo, combinada com pesquisa bibliográfica, em que se utilizou o método quantitativo/qualitativo e analítico. No contexto dos serviços ambientais se identificou um potencial favorável para a inserção aos mercados da produção de frutas abundantes na região. A regulamentação da política dos serviços ambientais poderá contribuir para aumentar a renda média das pequenas propriedades e favorecer a maior efetividade dessa política.

\section{Palavras-chave}

Amazônia. Políticas ambientais. Proambiente. Serviços ambientais.

\begin{abstract}
This paper aims to describe the factors that contribute to the lack of success in applying environmental public policies in the Amazon region, and how that had a decisive role in reaching the goals of Proambiente, in the Apiaú valley, Mucajaí county, estate of Roraima. This case study was achieved through descriptive and field research, combined with bibliographical research, in which we used quantitative/ qualitative methods, as well as analytical. Within the context of environmental services, we identified the potential for market insertion of regional fruits. Political regulation of environmental services will help increase the average income of small properties as well as the efficiency of those policies.
\end{abstract}

\section{Keywords}

Amazon region. Environmental policies. Proambiente. Environmental services. 


\section{INTRODUÇÃO}

Com a necessidade de se harmonizar o crescimento econômico e a utilização racional dos recursos naturais, a partir da década de 1960 inicia uma série de ordenação de políticas públicas em nível global, amparadas no chamado "Direito Intergeracional". Entre as diversas convenções ambientais destacamse a de Estocolmo, em 1972, e a Rio-92. Nestas convenções foram produzidos documentos importantes que nortearam as políticas ambientais em níveis global, nacional e regional, em busca de um modelo de desenvolvimento mais equilibrado. Em 1997, foi negociado e acordado Protocolo de Quioto, com metas definidas para reduzir o impacto das mudanças climáticas, em que os países se comprometiam em reduzir emissões de gases poluentes (PROTOCOLO..., 1997).

O Brasil passa a adotar essas políticas e a desenvolver projetos que objetivam o desenvolvimento sustentável. No histórico deste processo, originouse o Proambiente, como um programa de desenvolvimento rural sustentável para a Amazônia, oriundo da discussão dos movimentos sociais rurais da Amazônia Legal. Seu principal objetivo era o de remunerar os serviços ambientais para a compensação dos custos de oportunidade dos pequenos agricultores, que passavam a adotar um novo modelo de produção rural sustentável, com assistência técnica e extensão rural.

Neste sentido, este trabalho tem como objetivo descrever os fatores que contribuem para a falta de efetividade na aplicação das políticas públicas ambientais para a Amazônia e como estas questões influenciaram na consecução das metas do Proambiente. Portanto, analisa-se a concepção e a aplicação dessa política pública e sua relação com o desenvolvimento rural, no que tange às questões dos serviços ambientais, da estrutura social, econômica e ambiental da vicinal 07, polo do Proambiente no Apiaú, estado de Roraima.

Para tanto, a metodologia utilizada é de uma pesquisa descritiva, combinada com pesquisa bibliográfica e de campo, com estudo de caso específico, em que se utilizou o método quantitativo/qualitativo e analítico. Como técnica de pesquisa foi realizada entrevistas semiestruturadas, aplicado questionário socioeconômico ao universo de 16 pequenos proprietários rurais sob a área de influência do Proambiente, na vicinal 07 . No desenvolvimento do trabalho será demonstrado a aplicabilidade dessa política pública e o seu resultado no estado de Roraima. 


\section{POLÍTICAS AMBIENTAIS E PROAMBIENTE}

Na segunda metade do século XX, as sociedades dos países desenvolvidos começaram a perceber com nitidez o risco do esgotamento dos recursos naturais, fundamentalmente dos combustíveis fósseis. Com o advento de duas crises petrolíferas na década de 1970, o mundo começa a ter consciência da necessidade de se harmonizar crescimento econômico e utilização racional dos recursos naturais. Para tanto, precisava-se de uma coordenação de políticas públicas em nível global, amparadas no chamado "Direito Intergeracional", o que resulta em diversas políticas ambientais nos níveis global, nacional e local.

Para Graf (2005), as convenções representam a busca da governabilidade global ou "gestão globalmente compartilhada". As tentativas de institucionalizar essa gestão na área ambiental significam um avanço coerente com a necessidade de se trabalhar politicamente com as escalas globais.

Segundo Rios (2005, p. 87), o primeiro documento internacional que faz referência a este ramo do Direito foi a Declaração de Estocolmo, de 1972, a qual apregoava, em seu princípio inaugural, que "o homem tem a solene responsabilidade de proteger e melhorar o meio ambiente para a atual e às futuras gerações". Este trabalho traçava perspectivas pessimistas para o futuro da humanidade, caso prevalecesse as atuais tendências quanto ao tipo de modelo de desenvolvimento econômico adotado até então, o qual excluía a preocupação com a conservação de recursos naturais escassos.

Em 1987, a Comissão Brundtland incorporou aos documentos internacionais, com mais ênfase, a expressão "desenvolvimento sustentável", o qual se destaca como um tipo de produção econômica que garante a manutenção dos recursos naturais para o uso das futuras gerações (CMMAD, 1988, p. 46).

O desenvolvimento sustentável revela, praticamente, a apropriação do discurso ambiental pelas bases capitalistas, de certa forma o "marketing verde" como uma "tentativa de legitimar o sistema" (SACHS, 2000; STAHEL, 1995).

Paulatinamente, o conceito do desenvolvimento sustentável foi evoluindo para um tripé que iguala, com mesmo peso, as sustentabilidades ambiental, social e econômica. Ou seja, embora a origem do conceito de desenvolvimento sustentável (DS) esteja relacionada ao campo ambiental, o conceito foi aprimorado, diante do reconhecimento de que a sustentabilidade ambiental, ao longo do tempo, também depende das dimensões sociais e econômicas. No entanto, é fato que a maioria dos atores, ao utilizar o DS, direciona este tripé para o lado da sustentabilidade econômica, de modo que a prioridade ambiental novamente é colocada no final das prioridades. 
Em 1988, a Assembleia Geral das Nações Unidas (ONU) aprovou a resolução de 44/28. Nesta conferência surgiram tratados internacionais de grande relevância, nos quais os chefes de Estado presentes se comprometiam a trabalhar para alcançar o Desenvolvimento Sustentável através de 27 princípios gerais de atuação em meio ambiente e desenvolvimento. A Convenção de Mudanças Climáticas teve, até agora, impacto limitado, devido à baixa disposição dos EUA de abrir mão de suas emissões, tendo em vista a repercussão no seu desenvolvimento econômico e a fraca liderança do Japão (MARTINS, 1997).

Em 1997 foi negociado e acordado o Protocolo de Quioto, que entrou em vigor em março de 2005. Este teve como horizonte o ano de 2012; e planeja-se, como um primeiro passo, conseguir a estabilização das concentrações atmosféricas, que são a causa direta do problema. O acordo estabelece basicamente limites máximos de emissões de gases de efeito estufa aos países desenvolvidos. Tais limites levam a uma redução global de 5,2\% entre 2012 e 1990 (calculado como média do período desde 2008), quantidade que obviamente seria muito superior, ao assumir uma evolução das emissões sem controle.

Para ajudar os países desenvolvidos a alcançarem suas metas de redução de gases de efeito estufa, o Protocolo de Quioto estabeleceu três mecanismos flexíveis: o primeiro foi a implementação conjunta (Joint implementation), que possibilita a parceria entre países desenvolvidos, com o propósito de atingir suas metas de redução de emissões; o segundo mecanismo foi o comércio de emissões (Emissions Trading), também restrito a esses países; e, por fim, o Mecanismo de Desenvolvimento Limpo (MDL - Clean Development Mechanism), que permite a participação dos países em desenvolvimento. Este processo é o embrião da comercialização das reduções de emissões, atualmente popularizado por mercado de créditos de carbono (PROTOCOLO..., 1997).

Conceitualmente, os projetos de MDL são aqueles que, ao mesmo tempo em que promovem o desenvolvimento, também propiciam o sequestro de carbono ou simplesmente evitam a sua emissão na atmosfera. Esta é a única forma de inserção de países em desenvolvimento nas atividades estipuladas pelo Protocolo de Quioto. Isso porque os países desenvolvidos signatários, que se comprometeram a reduzir as emissões de gases poluentes, têm interesse em investir em projetos de MDL, que possuem um custo marginal de abatimento das emissões menor que em seus próprios territórios. Supõe-se que isso ocorra em países menos desenvolvidos. 


\section{POLÍTICAS AMBIENTAIS NA AMAZÔNIA}

No Brasil, e especificamente na Amazônia, nas quatro últimas décadas as políticas ambientais apoiaram-se fortemente no uso de regulamentações como leis, decretos e portarias, diretamente formulados pelos três níveis da administração pública. O objetivo foi frear o efeito antrópico sobre o bioma, reflexo da política de ocupação dirigida para a região, que teve seu eixo em projetos estruturantes, como estradas, energia e comunicações.

Atualmente, o Brasil continua a discutir questões recorrentes sobre a propriedade da terra; o usufruto das riquezas minerais encontradas nos subsolos das terras indígenas; o desmatamento crescente, amparado no custo de oportunidade; a biopirataria, presente no território amazônico; alternativas energéticas para o crescimento do país e a harmonização das políticas públicas, sobretudo as ambientais, com esta diversidade econômica, social e cultural.

A história de ocupação da Amazônia reflete o desejo de integração e de uma busca por atender aos anseios de uma classe dirigente ávida por reproduzir modelos econômicos exitosos em outras regiões do Brasil, para o atendimento da demanda externa crescente por commodities e produtos in natura. A intenção de evitar incursões estrangeiras foi preponderante para o início do processo em que o subsistema econômico predominava nas decisões, sem observação dos limites impostos pelo sistema maior, que é a biosfera, e que não apresentava sinais de escassez na época.

A partir da década de 1980, esta política de desenvolvimento entrou em decadência devido aos fatores macroeconômicos vividos pelo país. Se por um lado houve avanços com relação à integração da região ao restante do país e ao crescimento da renda, por outro, não houve avanço na redução das desigualdades sociais, pois, no caso da Amazônia, a concentração populacional nas áreas urbanas foi reflexo também de problemas relacionados ao campo.

Esta situação de exclusão aumentou a violência no campo e os conflitos entre fazendeiros, produtores rurais, garimpeiros, indígenas, posseiros e madeireiros, para garantir a posse da terra e dar alternativas para a sobrevivência na região. Consequentemente, os principais movimentos sociais, já amparados na Constituição de 1988, lideraram alianças com outros segmentos de representação, objetivando a luta pela reforma agrária, a implantação de reservas extrativistas, a demarcação de terras indígenas e pleiteando políticas públicas de saúde e educação (ALMEIDA, 1994).

As políticas públicas ambientais, alicerçadas nos acordos internacionais, ainda não atentaram para a devida problemática vivida pela Amazônia, 
consubstanciada ainda na ideia do poluidor-pagador e não na ótica do provedorrecebedor. Uma região provedora de serviços ambientais para o Brasil e para outras regiões requer políticas que remunerem aqueles que historicamente já ocupam a região e trazem consigo a responsabilidade de proteger a Amazônia, sem contrapartida.

\section{PROAMBIENTE}

No histórico deste processo, originou-se o Proambiente, como um Programa de Desenvolvimento Rural Sustentável para a Amazônia, oriundo da discussão dos movimentos sociais rurais da Amazônia Legal sobre a necessidade de superar a dicotomia entre a produção rural e a conservação ambiental. Sua área de influência foi dividida em 11 polos espalhados pela Amazônia Legal, com o objetivo de remunerar os serviços ambientais, para compensação dos custos de oportunidade dos pequenos agricultores, que passavam a adotar um novo modelo de produção rural sustentável, com assistência técnica e extensão rural.

Neste sentido, o Proambiente, como um Programa de Desenvolvimento Rural Sustentável, insere na agenda, a partir de 2003, a questão fundamental para a mudança de paradigma ambiental no presente século, que é a remuneração dos serviços ambientais, consorciada com o desenvolvimento de políticas agrícolas.

O Programa propõe mecanismos de transição do modelo vigente de ocupação e degradação, para um modelo de inclusão social e recuperação das áreas antropizadas, mediante a remuneração pelos serviços ambientais ofertados pelos pequenos agricultores familiares da Amazônia.

A proposta do Proambiente nasceu em 1999, da necessidade de elaboração de novos modelos de assistência técnica e de crédito para a agricultura familiar na Amazônia, e de superar a dicotomia entre a produção rural e a conservação ambiental. Os protagonistas dessa discussão foram as organizações de movimentos sociais, como a Federação dos trabalhadores na Agricultura (FETAG), o Movimento Nacional dos Pescadores (MONAPE), a Coordenação das Organizações Indígenas da Amazônia Brasileira (COIABE), o Conselho Nacional dos Seringueiros (CNS) e o Grupo de Trabalho Amazônico (GTA) (PROAMBIENTE, 2003).

A partir da proposta preliminar do Proambiente por essas organizações, em junho de 2003, foi incluído como programa da Secretaria de Desenvolvimento Sustentável do Ministério do Meio Ambiente, no Plano Plurianual 2004-2007. O gerenciamento do programa ficou sob a responsabilidade do Ministério do Meio

Novos Cadernos NAEA, v. 16, n. 1, Suplemento, p. 281-300, jun. 2013 
Ambiente (MMA). Entre as suas atribuições, o Ministério assumiu o papel de articular as ações de implementação junto às demais instâncias do governo e fazer a interlocução com as organizações da sociedade civil.

A essência principal desse programa se define como um programa de desenvolvimento rural socioambiental, direcionado aos produtores familiares. Estes adquirem um novo papel perante a sociedade, pois seus atores sociais deixam de ser apenas fornecedores de produtos primários, sendo valorizado o caráter multifuncional da produção econômica, associada à inclusão social e à conservação do meio ambiente. O programa pretendia, em sua concepção, o controle social das políticas públicas e a remuneração dos serviços ambientais prestados à sociedade brasileira e internacional (PROAMBIENTE, 2003, p.19).

Inicialmente, a implantação do Programa se deu com apoio da cooperação bilateral Brasil-Holanda, via Fundo Nacional do Meio Ambiente (FNMA). Em 2004 e 2005 foram implantados 11 polos pioneiros: Rio Capim, Transamazônica e Polo Ilhas do Marajó, no Pará; Laranjal do Jari, no Amapá; Rio preto da Eva, no Amazonas; Polo do Apiaú, em Roraima; Ouro Preto, em Rondônia; Juína, no Mato Grosso; Alto Acre, no estado do Acre; Baixada Maranhense, no Maranhão, e Polo do Bico do Papagaio, no Tocantins.

O Programa trabalhou inicialmente com cerca de 4.010 famílias. A sua execução alterou, de certa forma, o manejo da pequena propriedade, haja vista que, na média, $46 \%$ dos polos modificaram a forma de produção e de preservação. Resultados significativos foram alcançados nos polos de Juína (MT); Alto Acre (AC) e Bico do Papagaio (TO), que obtiveram índice de $100 \%$ ou próximo deste, na alteração da forma de manejo dos recursos naturais. Porém, destaca-se o Polo do Bico do Papagaio, que obteve a melhor relação custobenefício, considerando que teve um gasto por família de $\mathrm{R} \$ 1.558,00$, enquanto que os polos de Juína e Alto Acre tiveram um gasto per capita de $\mathrm{R} \$ 3.233,00$ e $\mathrm{R} \$ 2.545,00$, respectivamente, para obter $100 \%$ de suas metas cumpridas.

O Proambiente auxiliou satisfatoriamente muitas famílias de pequenos agricultores rurais, na compreensão do que representa uma APP e a Reserva Legal. Essa compreensão e reconhecimento criaram, em muitas famílias que fazem parte do Programa, a valorização da necessidade de recomposição e conservação das reservas nas propriedades/lotes e nos assentamentos. Houve o interesse pelo pagamento dos serviços ambientais (PSA) em todos os 11 polos, principalmente por parte das famílias que têm dificuldades de mão de obra e de recursos para plantar, preservar e recuperar APPs.

Para o pagamento da prestação pelos serviços ambientais, há o cumprimento de exigências técnicas e socioambientais, que são verificadas através 
de indicadores diretos (desmatamento evitado e sequestro de carbono) que têm a biomassa como indicador; e dos indicadores indiretos (água, solos, biodiversidade e redução do risco de fogo), que são verificados por meio do cumprimento dos padrões de certificação de serviços ambientais do Programa. A cada ano, grupos de beneficiários dos polos irão estabelecer seus acordos comunitários e receber auditorias de campo de uma prestadora de serviços de certificação de serviços ambientais (PROAMBIENTE, 2003).

Os principais serviços ambientais considerados para a remuneração pelo programa são: manutenção da qualidade da água, isto é, a minimização das cargas sedimentares, cargas de nutrientes, de químicos e salinidade; controle da erosão do solo e do assoreamento; manutenção dos habitats aquáticos, a redução da temperatura aquática por meio do sombreamento dos rios e córregos; sequestro de carbono pela floresta, removendo da atmosfera o GEE, através de atividades de florestamento e reflorestamento; emissões evitadas pela conservação da floresta em pé, ou desmatamento evitado e florestamento de espécies nativas, que aumentam a oferta de bens ambientais alimentares ou industriais, entre outros.

\section{CASO DE ESTUDO - VALE DO APIAÚ - RORAIMA}

O Vale do Apiaú, no município de Mucajaí, é um dos polos integrantes da política Proambiente. Localizado no estado de Roraima, integra a Região Norte e a Amazônia Legal (Figura 1). Roraima é um dos estados mais novos da Federação. Sua criação se deu através da Constituição Federal de 1988, contudo, concretizou-se como Unidade Federativa somente em 1991, com a instalação de sua estrutura político-administrativa e promulgação da primeira constituição do Estado, em 31 de dezembro de 1991.

Com 224.301,040 $\mathrm{km}^{2}$ distribuídos entre os 15 municípios, Roraima tem 450.479 habitantes, perfazendo uma baixa densidade demográfica, de 2,01 hab. $/ \mathrm{km}^{2}$, e alta taxa de urbanização, de 78\% (IBGE, 2010). O crescimento demográfico elevado e crescente nos anos de 1970 e 1980 (taxas anuais de 6,8\% e 10,4\%, respectivamente), decresceu para 2,6\% ao ano em 1990-1996. Porém, foi intenso, de 7\% ao ano, se tomado todo o período de 1996-2000.

O município de Mucajaí está localizado na região centro-oeste de Roraima. Sua denominação deve-se ao rio Mucajaí, em cujas margens foi implantada, em 1944, a Colônia Agrícola Fernando Costa, criada pelo Capitão Ene Garcez dos Santos, primeiro Governador do Território Federal do Rio Branco, que tinha como objetivo suprir a capital do estado de produtos agrícolas (FEMACT, 1993).

Novos Cadernos NAEA, v. 16, n. 1, Suplemento, p. 281-300, jun. 2013 
Figura 1. Localização da área de estudo. Apiaú, vicinal 07 Mucajaí: RR. Na imagem Landsat 7/ $\mathrm{ETM}^{+}$órbita ponto 232/58 de 17/03/2003, na composição 5(R) 4(G) 3(B).

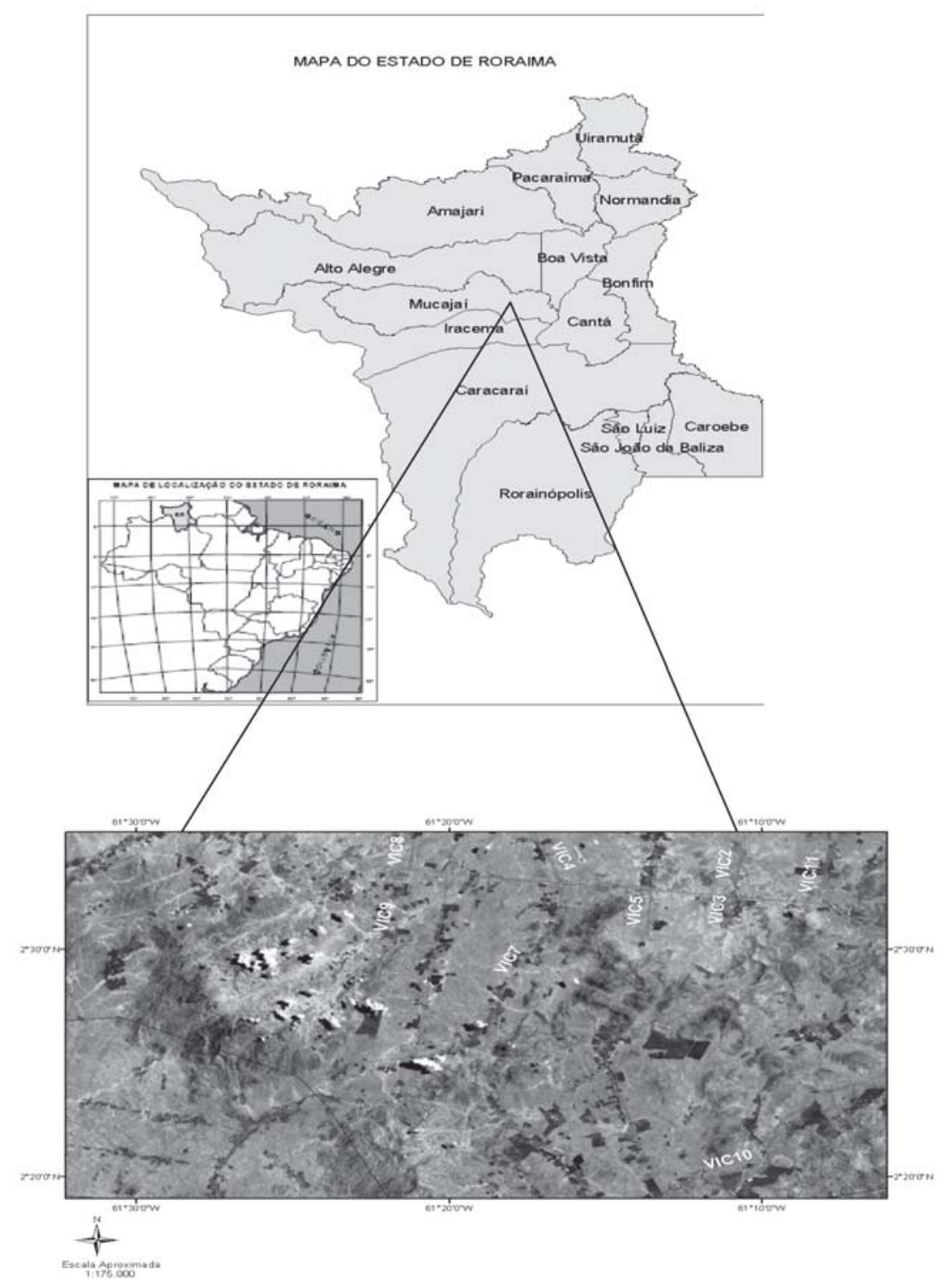

Fonte: IBGE/SEPLAN-RR.

Para Guerra (1952), foi no ano de 1951 que efetivamente começou a colonização nessa área do Mucajaí e ao longo da atual rodovia BR 174. Neste ano, foram trazidas 102 famílias. No início de 1952, chegaram mais 12 famílias, e 
em fins de 1953, mais 26 famílias. A partir da década de 1970, a 4 km das margens do rio Mucajaí, houve a instalação de uma unidade do $6^{\circ}$ Batalhão de Engenharia e Construção do Exército Brasileiro, encarregado de construir a BR 174, para ligar Boa Vista ao município de Caracaraí.

A povoação foi elevada à categoria de município em 1982, já com o seu núcleo urbano com área territorial de $23.601,7 \mathrm{~km}^{2}$, que foi desmembrada do município de Caracaraí. A sede municipal situa-se a uma altitude de $70 \mathrm{~m}$, nas coordenadas $60^{\circ} 54^{\prime} 00^{\prime \prime}$ oeste e $02^{\circ} 25^{\prime} 48^{\prime \prime}$ norte.

Segundo o censo demográfico do Instituto Brasileiro de Geografia e Estatística (IBGE, 2010), o município apresentou 14.792 habitantes, sendo $62 \%$ da população urbana e 38\% rural, abrangendo as povoações e vilas, entre elas: Apiaú, Rouxinho, Tamandaré e Vila Iracema, todas com um bom potencial agrícola, extrativista vegetal e atividade pecuarista. Economicamente, apresenta o $5^{\circ}$ maior PIB do estado, sendo destaque a produção de arroz, feijão, mandioca, melancia, milho, tomate e atividade pecuária extensiva (SEPLAN, 2010).

A área de estudo foi delimitada na Colônia Apiaú ${ }^{1}$, vicinal 07 . Trata-se de uma colônia agrícola implantada em 1980, localizada a $50 \mathrm{~km}$ do município de Mucajaí, centro do estado de Roraima. Foi a partir das colônias, pontos de fixação da população na zona rural, instaladas junto às estradas de integração, que a maior parte do território roraimense foi efetivamente ocupada e explorada, haja vista que dos quinze municípios do estado, oito tiveram origens em colônias oficiais. Sua principal atividade econômica é a agropecuária, da qual sobressai o extrativismo madeireiro, fruticultura, pecuária extensiva e criação de pequenos animais.

Ao longo dos 29 anos de ocupação, a região tem sido caracterizada por um intenso fluxo de migrantes, que vem conferindo diferentes usos ao solo e intensa prática de queimadas agrícolas. Este fluxo migratório origina-se dos estados nordestinos do Maranhão e Ceará. Geralmente a mão de obra utilizada é familiar, constituída pelo pai, mãe, filhos e agregados. Eventualmente ocorre o mutirão entre os produtores, nos períodos de preparo do solo, plantio, conservação e colheita, quando há maior necessidade mão de obra.

Esta região é caracterizada por grandes extensões de terra, com pastagens convertidas de florestas e pelo elevado fluxo de migrantes, que aceleraram o processo de desmatamento (BARBOSA, 2000). A vegetação original foi caracterizada pelo Projeto RADAMBRASIL (BRASIL, 1975) como um mosaico

A colonização é toda atividade oficial ou particular que se destine a promover o aproveitamento econômico da terra, pela sua divisão em propriedade particular ou em cooperativas (FEDERAÇÃO DOS TRABALHADORES E TRABALHADORAS NA AGRICULTURA DO ESTADO DE RORAIMA, 2003).

Novos Cadernos NAEA, v. 16, n. 1, Suplemento, p. 281-300, jun. 2013 
entre dois tipos de floresta tropical densa: a) submontanha em relevo dissecado (Fdn); b) sob baixas cadeias de montanhas (Fdt). Este último distribuído entre serras e serrotas locais.

\section{METODOLOGIA DO ESTUDO}

O estudo foi conduzido tanto na abordagem qualitativa quanto quantitativa. Para Monteiro (2003, p. 46), a abordagem qualitativa proporciona o aprofundamento da realidade concreta, desvendando os processos que se fazem entre o teórico e o empírico. Com relação à abordagem quantitativa, segundo Rutter e Abreu (apud MONTEIRO, 2003, p. 68) “justifica que os métodos utilizados são de modo geral vinculados para medir opiniões, reações, sensações, práticas, hábito de certo universo populacional".

Neste sentido, pela característica do estudo com dados empíricos e bibliográficos, quantitativos e qualitativos, primeiramente formalizou-se uma rede de informações, sendo este estudo realizado em três etapas distintas. Na primeira etapa buscou-se identificar e localizar o Polo do Apiaú, mediante contato com o corpo técnico da Empresa Brasileira de Pesquisa Agropecuária (EMBRAPA), Instituto Nacional de Colonização e Reforma Agrária (INCRA), Federação dos Trabalhadores em Agricultura do Estado de Roraima (FETAGRI/RR) e do Ministério do Meio Ambiente, através da Secretaria de Desenvolvimento Sustentável (SDS).

Na segunda etapa foi definido, elaborado e aplicado o questionário a 16 pequenos proprietários rurais sob a área de influência do Proambiente, na vicinal 07, de um universo de 68. Na formulação do mesmo, foram coletadas informações sobre: caracterização e composição familiar, dados físicos da propriedade rural, condições de moradia, equipamentos domésticos e produtivos, fonte principal e secundária da renda no lote, tecnologia e meio ambiente, a remuneração pelos serviços ambientais, o conhecimento do Proambiente, nível de organização e empoderamento dos pequenos agricultores, assistência técnica e extensão rural, e a atuação dos órgãos ambientais.

Finalmente, na terceira etapa, efetuaram-se as atividades computacionais para tratamento dos dados, usando a estatística descritiva que, segundo Fonseca (1996, p. 101), "se constitui num conjunto de técnicas que objetivam descrever, analisar e interpretar os dados numéricos de uma população ou amostra, que foram apresentados através de tabelas e gráficos", abordando o perfil socioeconômico dos pequenos agricultores da vicinal 07, do Polo do Apiaú. 


\section{RESULTADOS E ANÁLISE}

$\mathrm{Na}$ análise dos resultados, referente à origem e perfil das famílias, o aspecto abordado no estudo foi a origem dos agricultores nas unidades de produção familiar da vicinal 07. Nesta ordem, apresentam-se 50\% de maranhenses; 19\% de baianos; 13\% de cearenses e 19\% oriundos de outras Unidades da Federação. Verificou-se, também, que a média de idade dos envolvidos no Proambiente da vicinal 07 é de 51 anos. O tempo de residência em Roraima apresentou média de 22 anos, aproximadamente, no início da transformação do Território Federal de Roraima em Estado; e o tempo no lote com média de 11 anos.

Para Costa (2005), a unidade de produção familiar é, indistintamente, unidade de produção e consumo, que são as necessidades de consumo e segurança alimentar dos seus membros. É a referência primordial das decisões, as quais, por seu turno, sempre resultam de um balanço entre o peso das suas necessidades e o custo do esforço físico de seus atendimentos.

As estradas vicinais se alongam, segundo o desenho conhecido, como "espinha de peixe", transversalmente ao eixo da estrada principal, e formam a maior parte dos atuais 3 mil quilômetros de estradas estaduais. A construção e manutenção destas estradas são constantes devido à destruição causada nos períodos de chuvas, que vão de abril a agosto, conforme a Figura 2.

Figura 2. Vicinal 07, Apiaú.

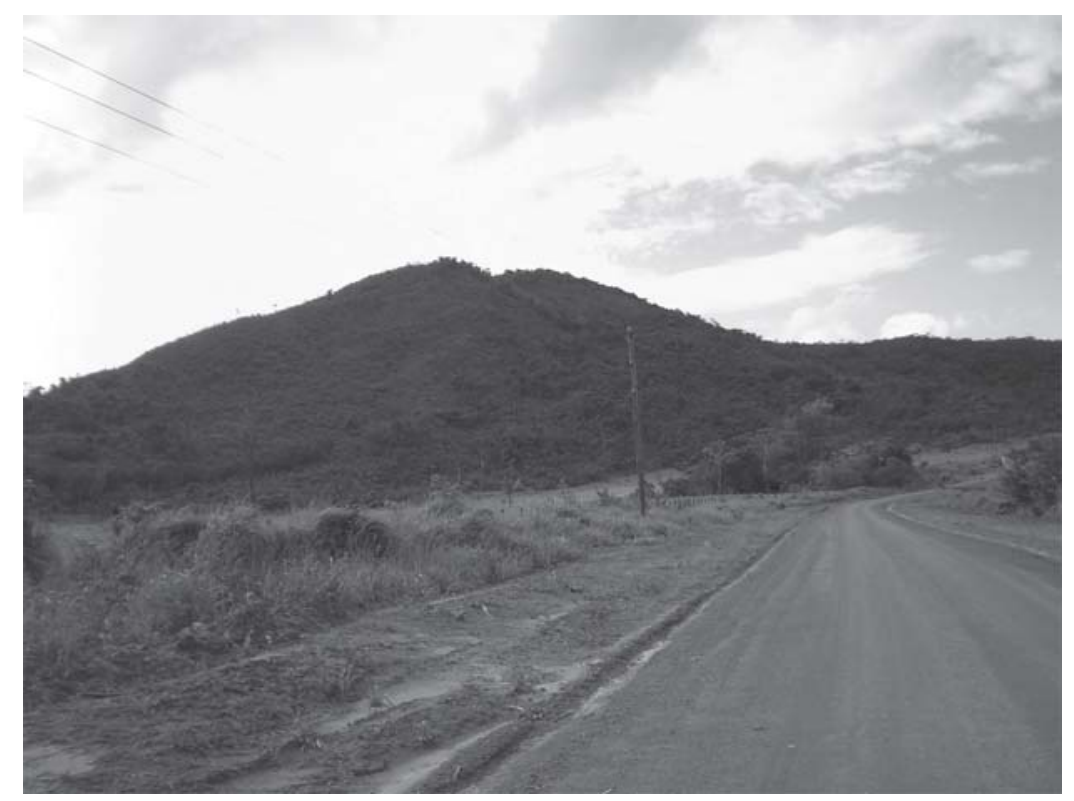

Foto: Luciano Amaral, 2008.

Novos Cadernos NAEA, v. 16, n. 1, Suplemento, p. 281-300, jun. 2013 
Quanto à estrutura etária e perfil educacional, ao verificar os resultados da estrutura etária dos proprietários dos lotes da vicinal 07, identificou-se que 6,3\% situam-se na faixa etária entre 33 a 41 anos; 37,5\% entre 41 e 49 anos; 25\% entre 49 e 57 anos; 12,5\% entre 57 e 65 anos e 18,8\% entre 65 e 73 anos.

Com relação à escolarização, observou-se que 12,5\% são analfabetos; 25\% são alfabetizados; $18,7 \%$ possuem o ensino fundamental incompleto; $25 \%$ têm o ensino fundamental completo; $6,3 \%$ possuem o ensino médio incompleto e 12,5\% possuem o ensino médio completo.

Percebe-se que a juventude do campo é atraída para as grandes cidades devido à dificuldade de acesso à escola e ao emprego. Mas, para Fernandes (2008) há uma atratividade do jovem pelo meio urbano ou, ainda, pelo estilo de vida urbano. Tal fato reflete-se também nos lotes da vicinal 07, em que são atraídos pela infraestrutura urbana da capital roraimense.

Referente às condições de moradia, no grupo dos 16 agricultores entrevistados, que é objeto deste estudo, as condições de moradia variam muito em termos de estrutura, isto é, os materiais usados na construção. Nos domicílios, em geral, $88 \%$ são de madeira e $12 \%$ são de alvenaria, coberta de telha de fibrocimento ou de barro, e piso de cimento, apresentando, em média, de 2 a 3 cômodos.

Em 100\% dos domicílios visitados existe luz elétrica da Rede da Companhia Energética de Roraima, o que permite aos agricultores a aquisição de bens de consumo duráveis, como a geladeira e televisão, que estão presentes em 100\% dos lotes dos pequenos agricultores. Também estão incluídos: máquina de lavar (75\%); de costura (43,8\%); aparelhos de DVD (31,3\%) e rádio $(68,8 \%)$.

Com relação às condições de saneamento, 93,8\% dos pequenos agricultores possuem água encanada, oriunda de poços artesianos, predominantemente de igarapés e rios, encontrados na região. Entretanto, 75\% dos domicílios possuem banheiros equipados de fossas sépticas.

Sobre a estrutura produtiva, de acordo com as entrevistas, 31,3\% desenvolvem a fruticultura e piscicultura; $25 \%$ se dedicam à fruticultura e à criação de pequenos animais; $19 \%$ apenas criam pequenos animais; $13 \%$ cultivam cereais para grãos como subsistência; $6,3 \%$ apenas cultivam cereais para grãos e $6,3 \%$ cultivam cereais para grãos, juntamente com a criação de pequenos animais.

Peculiarmente, $37,5 \%$ dos proprietários dos lotes não geram excedente para comercialização dos seus produtos no mercado, tendo em vista que é consumido tudo aquilo que se produz. Os demais 62,5\% geram excedente de produção, que tem como destino os mercados locais (no próprio lote) e no mercado de Boa Vista. Os principais produtos comercializados são as polpas de 
frutas, queijo, leite e suínos. A renda média auferida mensalmente é de $\mathrm{R} \$ 509,09$ e os demais tipos de rendimentos, como: pensão, aluguel, serviços temporários, entre outros, geram uma renda média mensal de $\mathrm{R} \$ 508,30$, distribuída a 56,3\% dos agricultores familiares, conforme a Figura 3.

Figura 3. Composição total da renda dos 16 pequenos produtores na vicinal 07

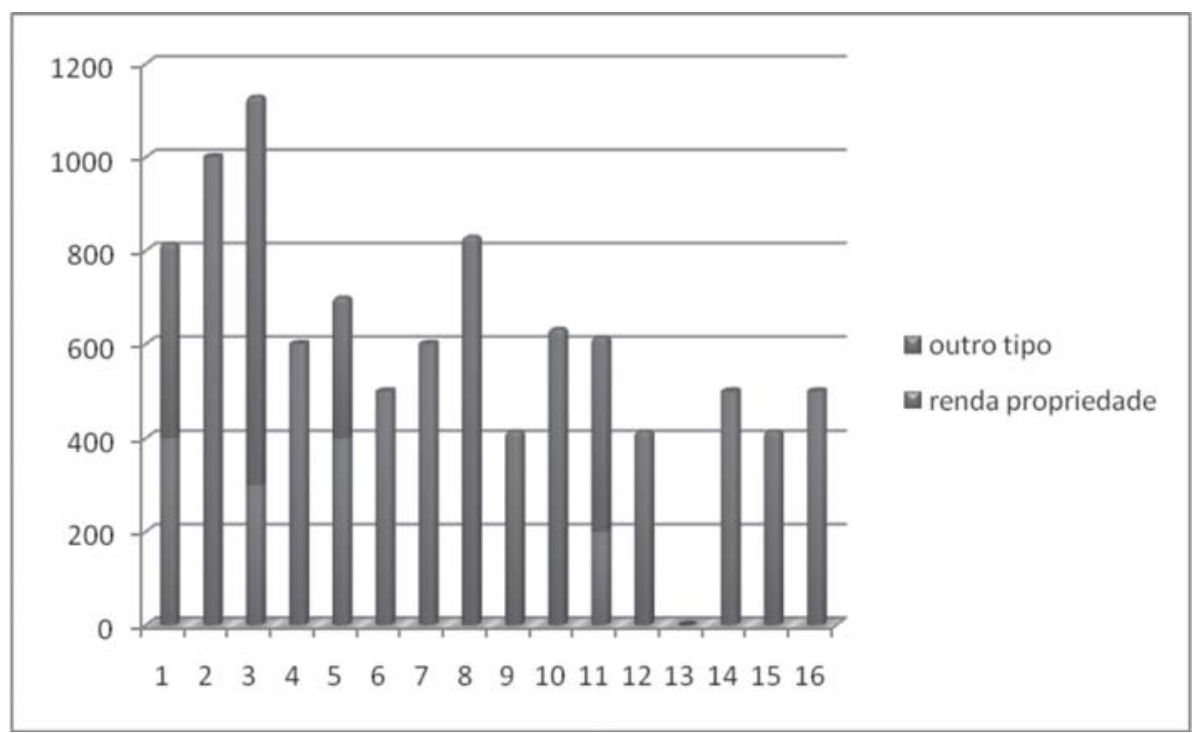

Fonte: Luciano Amaral, 2008.

Para Giovenardi (2003), o agregado agroindustrial é o que mais pode impulsionar a produtividade da unidade produtiva rural e a renda média do agricultor, porque lhe assegura uma produção contínua. A agroindústria representa, em média, $50 \%$ do valor da produção rural da agricultura moderna, por sua capacidade de gerar empregos, potencializar os investimentos e formular novas alternativas de comercialização e distribuição de produtos de boa qualidade, acessíveis a um maior número de consumidores, nos pontos mais afastados dos centros de comercialização.

Nos lotes onde os donos desenvolvem uma atividade de porte comercial, observou-se a capacidade de recorrer ao mercado de crédito bancário para obtenção de recursos para ampliar a produção, mediante a aquisição de equipamento de irrigação e insumos para a diversificação da produção. Verificou-se um grande interesse pela criação de peixes em cativeiro, haja vista que boa parte do peixe comercializado em Roraima vem do estado do Amazonas.

Um dos principais entraves ao desenvolvimento dessas pequenas unidades diz respeito à aquisição dos insumos para a produção, levando-se em conta que

Novos Cadernos NAEA, v. 16, n. 1, Suplemento, p. 281-300, jun. 2013 
representa um custo difícil de controlar e, por isso, o agricultor nem sempre os utiliza, porque faz contas prévias e sabe por experiência que o valor do produto não será o suficiente para cobri-los. Isto quer dizer que o risco de investir em custos - compra de insumos - ação para trás, deve ser compensado com riscos de investir em possibilidades de renda, isto é, em venda de produtos - ação para frente (GIOVENARDI, 2003, p. 49).

Dos $81 \%$ que já obtiveram financiamento para a sua produção, boa parte recorreu aos bancos: Brasil 31\%, Banco da Amazônia (BASA) (38\%) e Agência de Fomento do Estado de Roraima (AFERR) (8\%), isoladamente. Porém, os demais utilizaram um mix entre BASA/Banco do Brasil (15\%) e BASA/AFERR (8\%). A principal linha de crédito utilizada nos principais bancos foi o Programa Nacional de Agricultura Familiar (PRONAF), que é voltado especificamente para a agricultura familiar. Com relação à AFERR, os colonos têm reclamado que a sua linha de crédito atende em grande parte aos pecuaristas, financiando gado e arame para as propriedades.

$\mathrm{Na}$ análise sobre sustentabilidade, empoderamento e avaliação do Proambiente na vicinal 07 , identificou-se que o atual sistema de produção da maioria dos pequenos produtores rurais no estado de Roraima segue o tradicional método da "derruba e queima", onde se derruba, anualmente, uma área de floresta primária ou secundária de 0,5 a 1,0 ha para plantar culturas anuais. Entretanto, esta forma de uso da terra só mantém níveis aceitáveis de produtividade por, no máximo, dois anos, havendo o abandono da área, devido ao rápido declínio da fertilidade do solo e o aumento do número de plantas invasoras. Em seguida, inicia-se todo o ciclo em uma nova área de floresta, gerando maiores despesas e necessidade de mão de obra para o produtor. Os sistemas agroflorestais apresentam-se como uma alternativa de manejo sustentado de uso da terra, onde o produtor rural utiliza uma mesma área por muitos anos, desde que realize práticas de manejo (ARCO-VERDE, 2002).

O Programa Proambiente desenvolveu uma consciência ambiental quando propôs o uso alternativo ao fogo para a preparação do solo, através da mecanização agrícola, condicionamento adequado do lixo, preservação das margens dos igarapés e rios, e respeito ao limite de desmatamento de $20 \%$ da área dos lotes. Em 1999, a Embrapa e a APAA firmaram uma parceria para recomposição e ampliação dos Sistemas Agroflorestais, que consiste no plantio de frutíferas, como o açaí, maracujá, cupuaçu e ingá, além de uma crescente preocupação em recuperar as áreas de reserva legal e de preservação permanente que foram alteradas, introduzindo a plantação de madeiráveis como o paricá e o cedro doce. 
Neste sentido, o resultado disposto na pesquisa demonstra que 69\% dos colonos usam a mecanização em suas lavouras, enquanto que 31\% ainda utilizam o método tradicional da derruba e queima para preparação do solo. Com relação à preservação dos igarapés, dos 16 lotes entrevistados, 75\% possuem igarapés e, destes, 92\% preservam as suas margens.

A área de reserva legal, de certa forma, vem sendo respeitada dentro de seus limites, pois de toda a área de 1.020 ha, 76,2\% são preservadas e 23,8\% são utilizadas para o desenvolvimento da agropecuária. Cem por cento dos entrevistados veem a conservação do meio ambiente como fundamental. Para o Sr. Francisco, "quando se conserva a natureza, se conserva a vida, onde se provê o alimento. E além de nossas vidas, dos animais e de toda a cadeia alimentar".

Quando se avalia os órgãos ambientais, foi atribuída na pesquisa uma nota de 0 a 10, e suas respectivas justificativas. Verificou-se uma nota média geral 6,0 para o principal órgão ambiental presente no estado. A motivação real para esta nota foi devida aos órgãos ambientais não disporem de um tratamento igual na aplicação da legislação, tanto aos colonos, como aos grandes fazendeiros existentes na região. Existe uma grande burocracia para tirar as licenças ambientais nestes órgãos, causando um prejuízo de tempo e de recursos para os colonos. "Os órgãos ambientais não trabalham com a conscientização, tendo em vista que existe uma grande aplicação de multas de maneira arbitrária, sem dar alternativas de sobrevivência nos lotes" (opinião de um grupo de entrevistados).

Com relação ao empoderamento, foi avaliada a organização local para o desenvolvimento sustentável rural na vicinal 07 do Apiaú. Para tanto, foram atribuídos valores que variavam entre: 0 - nenhum nível de organização; 2,5 baixo nível de organização; 5,0 - médio nível de organização e 10,0 - alto nível de organização.

\section{CONCLUSÃO}

O Proambiente foi avaliado na pesquisa pela percepção do conhecimento do Programa e sua importância para a região envolvida. Verificou-se que a política pública precisa ter mais irradiação, considerando-se que $62,5 \%$ dos envolvidos conhecem o Programa.

Existe alguma desinformação generalizada nos polos sobre a situação da discussão do pagamento por serviços ambientais, tendo em vista que do total dos entrevistados, apenas 75\% conhece o seu significado. Destes, existe o interesse pelo pagamento na vicinal 07 , seja em forma de dinheiro ou em forma

Novos Cadernos NAEA, v. 16, n. 1, Suplemento, p. 281-300, jun. 2013 
de insumos, principalmente por parte das famílias que têm dificuldades de mão de obra e de recursos para plantar, preservar e recuperar as áreas de preservação permanente.

Percebeu-se a disposição dos agricultores em continuar com o Programa, mas que deve haver o aperfeiçoamento para o cumprimento das ações e proporcionar alternativas econômicas que são urgentes, para evitar o retorno ao uso do fogo e a retomada do êxodo rural para a cidade de Boa Vista, para onde a maioria dos filhos já saiu para concluir ou continuar os estudos.

Empiricamente, procurou-se avaliar a eficiência e efetividade do Proambiente na vicinal 07, no Polo do Apiaú. Para tanto, foi realizada uma pesquisa de campo em 16 pequenas propriedades rurais, para avaliação da estrutura social, econômica e ambiental. Foi constatada a aptidão da região para a fruticultura, haja vista as condições climáticas e o acesso aos mercados internos de Boa Vista e Manaus, como também ao mercado externo da Venezuela e Guiana. Procedimentos como o término da instalação de uma beneficiadora de frutas e a capacitação dos pequenos produtores quanto à comercialização, poderão induzir o desenvolvimento econômico da região, mediante parcerias com o governo e o terceiro setor.

Com relação à piscicultura, boa parte dos colonos iniciou o desenvolvimento da atividade, mas observou-se que há a necessidade de um acompanhamento técnico para evitar prejuízos. A renda média da propriedade fica a desejar porque em algumas propriedades as atividades produzidas são para a subsistência. Verificou-se que a renda complementar tem uma expressiva participação na composição total da renda das famílias. A regularização fundiária das propriedades pode melhorar o acesso ao crédito, para ampliação e dinamização da atividade produtiva.

O Programa, na vicinal 07, desenvolveu uma consciência ambiental quando propôs o uso alternativo do fogo para a preparação do solo, através da mecanização agrícola, condicionamento adequado do lixo, preservação das margens dos igarapés e rios, e o respeito ao limite de desmatamento. No entanto, verificou-se que o limite desta consciência ambiental está nos incentivos econômicos para avançar na questão da remuneração pelos serviços ambientais, que restringe a efetividade e eficácia do Proambiente, no seu objetivo básico de desenvolver a agricultura familiar rural na Amazônia.

Reconhece-se a hipótese da falta de sintonia entre os órgãos gestores, tanto nos outros polos da Amazônia legal quanto no polo do Apiaú, em Roraima, haja vista que a liberação dos recursos, prestação de contas e o feedback do Programa têm comprometido a execução plena do Proambiente. Comprova-se, também, mediante pesquisa de campo, um baixo nível de empoderamento na região, em 
que o isolamento dos colonos, pela falta de crédito nas políticas públicas, tem contribuído para a não fiscalização do Programa, sobretudo na liberação dos recursos da Assistência Técnica e Extensão Rural e, futuramente, na certificação dos serviços ambientais das propriedades.

Finalmente, salientamos que a não aprovação do Projeto de Lei 792/2007, que trata da remuneração dos serviços ambientais, coloca em cheque a efetividade das Políticas Públicas de desenvolvimento rural sustentável na Amazônia, como é o caso do Proambiente. Neste interregno, os estados, municípios e o terceiro setor podem criar mecanismos de incentivo aos pequenos agricultores rurais, seja na forma de subsídios aos insumos e tecnologias ou na forma de bolsas verdes e desenvolvimento da agroindústria rural, que tornem viável a produção agropecuária na Amazônia, sem a derrubada de nenhum hectare de floresta.

\section{REFERÊNCIAS}

ALMEIDA, A.W.B de. Universalização e localismo: movimentos sociais e crise dos padrões tradicionais de relação política na Amazônia. Belém: Museu Paraense Emílio Goeldi, 1994.

ARCO-VERDE, M. F. Utilização de sistemas agroflorestais em áreas de produtores rurais em Roraima. Boletim Pecuário, artigos técnicos, 22 jul. 2002.

BARBOSA. R.I. Erosão do solo na Amazônia: estudo de caso na região do apiaú, Roraima, Brasil. Acta Amazonica, v. 30, n. 4, p. 601-613, 2000.

BRASIL. Projeto RADAMBRASIL - volume 8. Rio de Janeiro: Ministério das Minas e Energia/Departamento de Recursos Naturais, 1975.

COMISSÃO MUNDIAL SOBRE MEIO AMBIENTE E DESENVOLVIMENTO -CMMAD. Nosso futuro comum. Rio de Janeiro: Fundação Getúlio Vargas, 1988.

COSTA, J.M.M da. Amazônia: desenvolvimento econômico, desenvolvimento sustentável e sustentabilidade de recursos naturais. Belém: UFPA, 1992.

COSTA, F. de A. Questão agrária e macropolíticas para a Amazônia. Estudos Avançados [online]., v. 19, n. 53, p. 131-156, 2005.

FEMACT-FUNDAÇÃO DO MEIO AMBIENTE E TECNOLOGIA DE RORAIMA. Roraima: o Brasil do Hemisfério Norte: Diagnóstico Científico e Tecnológico para o Desenvolvimento. Boa Vista: Ambtec, 1993.

Novos Cadernos NAEA, v. 16, n. 1, Suplemento, p. 281-300, jun. 2013 
FEDERAÇÃO DOS TRABALHADORES E TRABALHADORAS NA AGRILCULTURA DO ESTADO DE RORAIMA. Avaliação do Proambiente: Programa de Desenvolvimento Socioambiental da Produção Familiar Rural. Brasília: 2003.

FERNANDES, B.M. (Org.). Reforma Agrária e Desenvolvimento: desafios e rumos da política de assentamentos rurais. Brasília, DF: MDA; São Paulo: Uniara, 2008.

FONSECA, J.S da. Curso de Estatística. São Paulo: Atlas, 1996.

GIOVERNARDI, E. Os pobres do campo. Porto Alegre: Tomo Editorial, 2003.

GRAF, R. Política ambiental transversal: experiências na Amazônia brasileira. 2005. Dissertação (Mestrado) Universidade de Campinas, Campinas, 2005.

GUERRA, A.T. Estudo Geográfico do Território do Rio Branco. Rio de Janeiro: IBGE, 1952.

INSTITUTO BRASILEIRO DE GEOGRAFIA E ESTATÍSTICA. Censo populacional 2010. Disponível em: <http://www.ibge.gov.br.> Acesso em: 10 ago. 2012.

MARTINS, P. R. Reconstrução ecológica da sociedade industrial. In: ENCONTRO DA ECO-ECO , 2, 1997. São Paulo. Anais... São Paulo: Sociedade Brasileira de Economia, 1997.

MONTEIRO, H. de C. Guia para elaboração de projetos de pesquisa para trabalhos de conclusão de curso. Belém: [s.n.], 2003.

PROAMBIENTE: Programa de Desenvolvimento Socioambiental da Produção Familiar Rural (Conservação ambiental e vida digna no campo). Proposta definitiva da sociedade civil. Roraima, Julho de 2003. 32 p.

PROTOCOLO DE QUIOTO. The UN Framework Covention on Climate Change. 1997. Disponível em: <http://unfccc.int/resource/docs/convkp/ kpeng.pdf. $>$ Acesso em: 12 fev. 2008.

RIOS, A.V. O Direito e o Desenvolvimento Sustentável: Curso de Direito Ambiental. São Paulo: Instituto Internacional de Educação do Brasil, p.86122,2005 .

SACHS, I. Ecodesenvolvimento: crescer sem destruir. São Paulo: Vértice, 1986. 
SACHS, W. Meio Ambiente. In: SACHS, W. Dicionário do desenvolvimento: Guia para o conhecimento como poder. Petrópolis: Vozes, 2000.

SECRETARIA DO PLANEJAMENTO E DESENVOLVIMENTO DE RORAIMA. Produto Interno Bruto Estadual e Municipal. Boa Vista, 2010.

STAHEL, A. W. Capitalismo e entropia: os aspectos ideológicos de uma contradição e a busca de alternativas sustentáveis. In: CAVALCANTI, C. (Org.). Desenvolvimento e natureza: estudos para uma sociedade sustentável. São Paulo: Cortez, 1995. 